\title{
CARACTERIZACIÓN DE LA VEGETACIÓN A LO LARGO DE UNA GRADIENTE ALTITUDINAL EN LA COMUNIDAD DE COCHAHUAYCO, CUENCA MEDIA DEL RÍO LURÍN, LIMA
}

\section{VEGETATION CHARACTERIZATION ALONG AN ALTITUDINAL GRADIENT IN THE COCHAHUAYCO COMMUNITY, MIDDLE BASIN OF THE LURIN RIVER, LIMA}

\author{
Daniel Ramos ${ }^{1}$, Viviana Castro ${ }^{2}$ y Edgar Sánchez ${ }^{3}$
}

\begin{abstract}
Resumen
Se cuentan con diversos trabajos sobre vegetación y caracterización de ecosistemas en los Andes occidentales del centro del Perú; sin embargo se considera que el grado de conocimiento sobre la vegetación de la serranía limeña es aún limitado. Por tal motivo, se realizó un estudio de la vegetación en la cuenca media del río Lurín, departamento de Lima. El objetivo fue caracterizar la vegetación de las zonas altas de la comunidad de Cochahuayco según la gradiente altitudinal, de 1720 hasta 2957 msnm, en función a muestreos realizados y a observaciones de campo. Se establecieron ocho unidades de muestreo a lo largo de la gradiente, siguiendo un modelo de muestreo sistemático con arranque aleatorio. Las parcelas fueron evaluadas de forma trimestral desde Julio-2009 hasta Julio-2010. Se diferenciaron cinco unidades de vegetación, en base a la composición, abundancia y cobertura de las especies del estrato arbustivo. Estas unidades fueron: Zona de Cactáceas (entre 1720 y 2000 msnm), donde dominaron los cactos Haageocereus acranthus y Espostoa melanostele; Zona de Bastardia (entre 2000 y $2230 \mathrm{msnm}$ ), donde dominó el arbusto Bastardia bivalvis; Zona de Arbustos Altos (entre 2230 y 2500 msnm), donde dominaron los arbustos Euphorbia cf. laurifolia y Perymenium jelskii; Zona de Arbustos Subespinosos (entre 2500 y 2850 msnm), donde dominó el arbusto Verbesina saubinetioides; y Zona de Arbustos Espinosos (entre 2850 y $2957 \mathrm{msnm}$ ), con la dominancia del arbusto espinoso Proustia cuneifolia. Las dos primeras unidades estarían comprendidas dentro de la zona de vida de Matorral desértico subtropical y las otras tres en la Estepa espinosa montano bajo, y a su vez todas estas pertenecerían al tipo de cobertura de Matorral arbustivo.

Palabras clave: Densidad vegetal, cobertura vegetal, composición de especies, unidades de vegetación, estrato arbustivo, zonas de vida, serranía limeña.
\end{abstract}

\begin{abstract}
There are many studies on vegetation and ecosystem characterization in the occidental slope of the Central Andes of Peru. However the knowledge of the vegetation of the highlands of Lima is limited. Therefore, we conducted a study of the vegetation in the middle basin of the Lurin river, department of Lima. The aim was to characterize the upland vegetation of the Cochahuayco community according to an altitudinal gradient, ranging from 1720 to 2957 masl, based on samples and field observations. We established eight sampling units along the gradient, following a systematic sampling model with random start. The sampling units were evaluated on a quarterly basis from july-2009 to july-2010. Five vegetation units were differentiated, based on the composition, abundance and coverage of species of the shrub layer. These units were: Cacti Zone (between 1720 and 2000 masl), where Haageocereus acranthus and Espostoa melanostele were the dominant cacti; Bastardia Zone (from 2000 to 2230 masl), where Bastardia bivalvis was dominant; Tall shrubs Zone (from 2230 to 2500 masl), where Euphorbia cf. laurifolia and Perymenium jelskii were dominant; Sub-thorny shrubs Zone (from 2500 to 2850 masl), where Verbesina saubinetioides was dominant; and Thorny Shrubs Zone (from 2850 to 2957 masl), where Proustia cuneifolia was dominant. The first two units fell within the Subtropical desert scrub life zone, and the other three in the Lower montane thorn steppe life zone; all these belonged to the shrub thicket coverage type.
\end{abstract}

Key words: Plant density, plant cover, species composition, vegetation units, shrub layer, life zones, Lima highlands. 


\section{Introducción.}

En la actualidad, se cuenta con distintos trabajos sobre clasificaciones ecológicas y de vegetación para los Andes occidentales del centro del Perú, los que fueron desarrollados en un esfuerzo por diferenciar y delimitar la heterogeneidad de las condiciones ambientales y de la vegetación a distintas escalas espaciales. Así mismo, el enmarcar las características de determinados ambientes permitiría aplicar diferentes criterios según la escala, en la toma de decisiones sobre su conservación y manejo.

Para la sierra del departamento de Lima se cuenta con algunos trabajos sobre caracterizaciones de vegetación, siendo el realizado por Weberbauer (1945) el que brinda un marco general en las vertientes occidentales de los Andes del Perú central. Según este autor, basado en características fitogeográficas, en el sector andino se pueden distinguir dos pisos de vegetación entre los 1000 y 3900 msnm. Así mismo, en el mapa de cobertura vegetal del Perú elaborado por el MINAM (2012), se reconoce al Matorral arbustivo como el tipo de cobertura característico entre los 1500 y 3800 msnm de la zona central de la región occidental andina. Esta clasificación estuvo en función de la condición de humedad del terreno, de la fisionomía de la vegetación y de la geoforma.

Considerando una menor escala espacial, en la investigación de la ONERN (1975) realizada en el marco del proyecto Marcapomacocha, se determinó las zonas de vida en las cuencas del río Chillón, Rímac y Lurín. En esta fuente se describen las distintas características meteorológicas, orográficas, de vegetación, de composición de especies, del tipo de uso de la tierra y sobre sus potencialidades ecológicas y económicas, correspondientes a cada una de las tres zonas de vida descritas entre los 800 y 3800 msnm. El estudio fitosociológico de Galán de Mera et al. (2004) realizado en los valles de Santa Eulalia, Rímac, Chillón y San Bartolomé, entre los 1000 y alrededor de los 4500 msnm, reconoció dos grandes provincias de vegetación. Este trabajo se basó en el conocimiento de la flora de cada territorio y su distribución, determinando sus respectivas asociaciones según la dominancia de especies. Por otro lado, Valencia y Franke (1980) realizaron un trabajo más específico, abarcando una ladera del margen derecho del río Seco, área donde se encuentra el bosque de Zarate, ubicada en la cuenca del río Rímac. Estos autores identificaron siete zonas de vegetación distribuidas según la altitud entre los 1800 y alrededor de los 3800 msnm.

En los trabajos mencionados anteriormente, se reconoce al gradiente altitudinal como factor determinante en la variación y en la dominancia de especies, y por tanto de la vegetación. La aridez del ambiente disminuye conforme la altitud, debido a la progresiva reducción de la temperatura y a los mayores niveles de precipitación según la altitud. En general, la vegetación en la sierra de Lima presenta diversas características de xerofitismo, dominando especies suculentas con metabolismo CAM, arbustos en su mayoría caducifolios y hierbas anuales, resultante de las condiciones áridas y de la marcada estacionalidad en las precipitaciones (Weberbauer, 1945; ONERN, 1975). Por otro lado, la variación espacial y temporal de la vegetación condiciona el desarrollo de determinadas actividades económicas. Dependiendo de la disponibilidad de especies forrajeras y del desarrollo vegetativo, cada unidad de vegetación presenta diferente grado de importancia ganadera y de extracción de recursos, los que a su vez han sido condicionados por los niveles de precipitación precedentes (ONERN, 1975; Terradas, 2001).

No obstante estas caracterizaciones de la vegetación, se puede considerar que el grado de conocimiento sobre la vegetación de la serranía limeña, principalmente en la cuenca del río Lurín, es limitado. En general, los ecosistemas de zonas áridas suelen ser pobremente estudiados con fines de conservación, en comparación a humedales o áreas selváticas (Prina \& Alfonso, 2002; Soriano \& Ruiz, 2003). Esto se reflejaría en la reducida representación que tienen los ecosistemas de las vertientes occidentales de los Andes del Perú dentro del SINANPE, tal como ha sido señalado por Rodríguez \& Young (2000) para las regiones Matorral desértico y Mesoandina, en las que menos del $2 \%$ de sus respectivos territorios a nivel nacional se encuentran protegidos. Lo anterior sugiere un esfuerzo limitado en el grado de protección para estos ambientes y para los procesos que ahí ocurren.

El objetivo del presente trabajo fue caracterizar la vegetación según la gradiente altitudinal, entre 1720 y 2957 msnm, en las zonas altas de la comunidad de Cochahuayco, cuenca media del río Lurín. Esto fue posible mediante la información generada a partir del establecimiento de parcelas en la gradiente, así como de las observaciones de campo realizadas durante los recorridos hechos en el área de estudio, de forma trimestral desde julio-2009 hasta julio-2010.

\section{Materiales y métodos.}

Área de estudio.

El área de estudio comprendió una ladera de las zonas altas de la Comunidad Campesina de Cochahuayco, abarcando una gradiente altitudinal de 1720 hasta 2957 msnm. Estuvo limitada por las localmente llamadas quebradas de Cochahuayco y de Pishihuayqui, además de la quebrada de Tanquire en el sector más elevado (Figura 1). Esta ladera presenta especial interés para los pobladores locales debido a que en ella se encuentra una importante vía de acceso hacia las zonas altas y se desarrollan actividades ganaderas.

La Comunidad Campesina de Cochahuayco pertenece al distrito de Antioquia, provincia de 
Huarochirí, departamento de Lima, Perú. El pueblo se ubica en las coordenadas geográficas 1205'28', Latitud Sur y 76³0'20', Longitud Oeste, a una elevación de 1624 msnm, aproximadamente en el kilómetro 65 de la carretera Lima-Huarochirí. Geográficamente, Cochahuayco pertenece a la cuenca media del río Lurín. Esta zona presenta dos periodos estacionales, donde la época lluviosa suele extenderse desde noviembre hasta abril, mientras que la época seca durante el resto del año. Es durante la época lluviosa, que los ganaderos locales y foráneos tienden a asentarse en los sectores más elevados para aprovechar las pasturas y otras plantas de carácter estacional (Ramos, 2013). La vegetación natural es de tipo xerófita, donde predominan cactáceas, arbustos espinosos en su mayoría caducifolios y hierbas anuales (Weberbauer, 1945; ONERN, 1975).

Según la ONERN (1975), en el sector de la cuenca evaluada se pueden distinguir dos zonas de vida: (a) el Matorral desértico subtropical (md-ST), que se extiende desde los 800 hasta los 2100 msnm, y presenta un clima árido y semicálido con valores de precipitación promedio anual de $125 \mathrm{~mm}$ y temperatura promedio de $18{ }^{\circ} \mathrm{C}$; y (b) la Estepa espinosa montano bajo (ee-MB), que comprende desde los 2100 hasta los $3200 \mathrm{msnm}$, y presenta un clima semiárido y templado con precipitaciones medias anuales de $350 \mathrm{~mm}$ y temperatura promedio de $14.4^{\circ} \mathrm{C}$. Teniendo en cuenta lo señalado por RivasMartínez et al. (1988) sobre los pisos bioclimáticos andinos del Perú, la primera zona de vida correspondería al piso Termoandino y la segunda al Mesoandino. Así mismo, descripciones más recientes sobre los tipos de coberturas del Perú desarrollado por el MINAM (2012), el área de estudio estaría incluida dentro del Matorral arbustivo.

Muestreo.

La evaluación en campo se realizó estableciendo 8 unidades de muestreo a lo largo de la gradiente altitudinal, siguiendo un modelo de muestreo sistemático con arranque aleatorio. La ubicación de la primera unidad de muestreo se escogió al azar, a partir de la cual se dispuso el resto de unidades a una distancia aproximada de $500 \mathrm{~m}$ en la horizontal sobre el mapa topográfico de Antioquia (hoja: 25-I-NE) (COFOPRI, 2007). Las unidades de evaluación, en forma ascendente según la gradiente, fueron nombradas como Pampa Triste baja (1744 msnm), Pampa Triste media (1868 msnm), Pampa Triste alta (1933 msnm), Corralillo (2015 msnm), Vizcachera (2295 msnm), Mirador (2609 msnm), Cucche (2765 msnm) y Malca (2900 msnm) (Figura 1). Estas unidades de muestreo fueron evaluadas cada tres meses a partir de julio del 2009 hasta julio del 2010, siendo en total cinco salidas de campo. De esta manera se procuró evaluar fechas representativas de ambas épocas (seca y lluviosa) dentro de un ciclo anual. Las fechas de muestreo constaron de tres días comprendidos a finales de los meses de julio y octubre del 2009, y de enero, abril y julio del 2010.

En cada unidad de muestreo se establecieron dos parcelas de 1 x $1 \mathrm{~m}$ para el estrato herbáceo (hierbas) y una parcela de $5 \times 5 \mathrm{~m}$ para el estrato arbustivo (arbustos y cactos) (Mueller-Dombois \& Ellenberg, 1974; Matteucci \& Colma, 1982), considerando su representatividad respecto al paisaje de vegetación circundante. Las variables consideradas fueron densidad y cobertura. En las parcelas del estrato herbáceo se dispuso una cuadricula de 10 x 10 líneas (separadas cada $10 \mathrm{~cm}$ ), restringiendo para la evaluación a aquellas plantas cuyo brote coincidía con alguna de las intersecciones. En las parcelas del estrato arbustivo, para la densidad se consideraron a todas las plantas cuyo tronco se encontraba dentro de la parcela, mientras que para la cobertura se consideró a todas las plantas cuya copa se encontraba dentro de la parcela, aun si su tronco estuviese fuera. Así mismo, la cobertura fue calculada de forma individual para cada planta mediante el método de diámetro de copa (Mueller-Dombois \& Ellenberg, 1974), el cual consiste en la medición del diámetro mayor y de su perpendicular (D1 y D2), siendo luego reemplazadas en la fórmula:

$$
\text { Cobertura }=\left(\frac{D 1+D 2}{4}\right)^{2} * \pi
$$

Así mismo, durante los recorridos por el área de estudio a lo largo del periodo de evaluación, se realizaron observaciones de campo. En ellas, se registró la distribución y abundancia relativa de aquellas especies notorias (por su representatividad en el paisaje y facilidad de determinación), que no necesariamente estuvieran incluidas en las parcelas, a lo largo de la gradiente altitudinal.

Las muestras vegetales fueron determinadas en el Herbario MOL del Departamento Académico de Biología de la Universidad Nacional Agraria La Molina (UNALM), y por especialistas botánicos para ciertos grupos específicos. Por otro lado, las cactáceas fueron determinadas en campo, teniendo como referencia los trabajos realizados por Calderón et al. (2004), Castro (2006) y Ostolaza (2006), y por medio de comparaciones con ejemplares del Jardín Botánico Octavio Velarde Núñez de la UNALM. La nomenclatura científica siguió las determinaciones aceptadas por el Missouri Botanical Garden (Tropicos.org, 2015).

Dado que en la vertiente occidental de los Andes del centro del Perú, las formas de vida dominantes son los arbustos y los cactus (Weberbauer, 1945; MINAM, 2012), y que no se contó con suficientes registros para el estrato herbáceo (como se explica más adelante), es que los análisis realizados para la presente caracterización de la vegetación se centraron en lo reportado para el estrato arbustivo. 
Análisis de Datos.

Se calculó un índice de valor de importancia (IVI) a partir de un índice derivado de Cottan (Matteucci \& Colma, 1982), en función a la ponderación entre las variables de densidad y de cobertura de las especies dentro de cada una de las parcelas de muestreo. Con este IVI se representó de mejor manera la importancia ecológica de aquellas especies que pueden contar con varios individuos, pero de escasa cobertura, y de aquellas poco abundantes pero con coberturas mayores. El IVI fue expresado en porcentaje y fue calculado a partir de:

$$
I V I=\left(\frac{n i}{N}+\frac{c i}{C}\right) * 100 \%
$$

Dónde: "ni" es el número de individuos de la especie "i"; "N" es el número total de individuos; "ci" es la cobertura de la especie "i”"; y "C" es la cobertura total, dentro de una determinada parcela. El valor máximo del IVI fue de $200 \%$.

Se utilizó el análisis de cluster en base al IVI de las especies, para evidenciar la similaridad entre las parcelas del estrato arbustivo. Esto se realizó en función al criterio del coeficiente de Raup-Crick, que considera la presencia-ausencia de especies, y al criterio de similitud de Morisita, que está basado en la abundancia de las especies (Krebs, 1999). Estos dendrogramas fueron elaborados utilizando el programa PAST versión 1.7 (Hammer, 2011), y fueron realizados para cada una de las cinco fechas de evaluación. En el presente estudio solo se presentan los IVIs y los dendrogramas generados durante octubre-2009 y abril-2010, debido a que estas fechas han sido consideradas como representativas de las épocas seca y lluviosa respectivamente, para el área de estudio durante el ciclo anual estudiado (Ramos, 2013). Así mismo, se realizó una comparación de los niveles de cobertura total entre las parcelas del estrato arbustivo. Para ello se consideró a cada fecha de evaluación como una repetición, teniendo en cuenta que el rango de variación temporal en los niveles de cobertura para cada parcela fue relativamente bajo. Esto permitió la generación de un gráfico de intervalos de confianza, mediante el programa MINITAB versión 14 (Daniel, 2002). En base a la información generada a partir de los análisis de cluster y de los niveles de cobertura, se realizó un agrupamiento de las parcelas del estrato arbustivo según sus semejanzas.

Para la presente caracterización de las unidades de vegetación a lo largo de la gradiente altitudinal, se tuvo en cuenta los análisis de agrupamiento realizados para las parcelas del estrato arbustivo. Así mismo, como información complementaria a la obtenida por los muestreos, se consideraron las observaciones de campo realizadas a lo largo del periodo de evaluación, durante los recorridos hechos en los paisajes que abarcaron el área de estudio. Para esto último, también se tuvo en cuenta a aquellas especies notorias (por su representatividad en el paisaje y facilidad de determinación), que no necesariamente estuvieron incluidas en las parcelas, señalando su distribución a lo largo de la gradiente. Se tomó como referencia el trabajo de Valencia \& Franke (1980) para la denominación de las unidades de vegetación.

\section{Resultados.}

Composición de especies.

Durante el periodo evaluado, dentro de las parcelas de ambos estratos se diferenciaron 34 especies de plantas. De éstas, 29 especies pertenecieron a 12 familias, en tanto que las otras cinco especies no pudieron ser determinadas (Tabla 1). Las familias con mayor riqueza de especie fueron Asteraceae con 8 especies (23.5\% del total de especies), Fabaceae con cuatro especies (11.8\%) y Cactaceae, Euphorbiaceae y Poaceae con tres especies cada una (8.8\% cada una). Cabe señalar que las 7 familias restantes representaron el 23.5\% del total de especies, mientras que aquellas plantas no determinadas fueron el $14.7 \%$. Así mismo, fue posible el reconocimiento de otras especies que se encontraban fuera de las parcelas de evaluación, las cuales son mostradas en el Anexo 1, como parte de una contribución florística para el área de estudio. En cuanto a las formas de vida, los arbustos fueron los más representativos con 19 especies (55.9\% del total de especies), mientras que las hierbas y los cactos tuvieron $12 \quad(35.3 \%) \quad y$ tres $\quad(8.8 \%)$ especies respectivamente.

Análisis de similaridad.

En función a la ponderación de la densidad y la cobertura, se determinó el IVI de las especies de plantas que se encontraron en las 8 parcelas del estrato arbustivo. La parcela de Pampa Triste media (1868 msnm) mostró mayor número de especies, siendo 7 especies, mientras que las parcelas de Pampa Triste baja (1744 msnm) y Pampa Triste alta (1933 msnm) tuvieron una y cero especies respectivamente (Tabla 2).

Los análisis cluster mostraron la misma tendencia de asociación entre parcelas durante las cinco fechas de muestreo. Considerando la presencia-ausencia de especies del estrato arbustivo (criterio de Raup-Crick), se diferenciaron cuatro grupos de parcelas a un nivel de similaridad del 70\% (Figura 2A). El primer grupo lo conformaron las parcelas de Pampa Triste baja (1744 msnm) y Pampa Triste media (1868 msnm), las que estuvieron ubicadas a menor altitud y en las cuales se encontró al cacto Haageocereus acranthus, aunque con una jerarquía de abundancia distintas. La primera parcela solo presentó a esta especie de cacto, mientras que la segunda parcela mostró mayor número de individuos y especies de plantas, siendo las principales Encelia canescens y Dalea carthagenensis. La parcela de Pampa Triste alta (1933 msnm) conformó el 
Tabla 1. Lista de especies vegetales registradas dentro de las parcelas del estrato arbustivo y herbáceo. A, arbusto; C, cacto; H, hierba. 1, Pampa Triste baja (1744 msnm); 2, Pampa Triste media (1868 msnm); 3, Pampa Triste alta (1933 msnm); 4, Corralillo (2015 msnm); 5, Vizcachera (2295 msnm); 6, Mirador (2609 msnm); 7, Cucche (2765 msnm); 8, Malca (2900 msnm).

\begin{tabular}{|c|c|c|c|}
\hline Familia & Especies & Habito & Paisajes \\
\hline Acanthaceae & Dicliptera sp. & A & 7 \\
\hline \multirow[t]{8}{*}{ Asteraceae } & Bidens exigua Sherff & $\mathrm{H}$ & $1,2,3,4$ \\
\hline & Encelia canescens Lam. & A & $1,2,3,4$ \\
\hline & Helogyne sp. & A & $1,2,3,4$ \\
\hline & Ophryosporus galioides (DC.) R.M. King \& H. Rob. & A & $1,2,3$ \\
\hline & Perymenium jelskii (Hieron.) S.F. Blake & A & $5,6,7$ \\
\hline & Proustia cuneifolia D. Don & A & $6,7,8$ \\
\hline & Tagetes multiflora Kunth & $\mathrm{H}$ & $6,7,8$ \\
\hline & Verbesina saubinetioides S.F. Blake & A & $5,6,7,8$ \\
\hline Boraginaceae & Boraginacea-1 & A & 2 \\
\hline \multirow[t]{3}{*}{ Cactaceae } & Armatocereus matucanensis Backed. ex A.W. Hill & $\mathrm{C}$ & $3,4,5,6,7,8$ \\
\hline & Austrocylindropuntia subulata (Muehlenpf.) Backeb. & $\mathrm{C}$ & 8 \\
\hline & Haageocereus acranthus (Vaupel) Backeb. & $\mathrm{C}$ & $1,2,3,4$ \\
\hline \multirow[t]{3}{*}{ Euphorbiaceae } & Cnidoscolus cf. basiacanthus (Pax \& K. Hoffm.) J.F. Macbr. & A & $2,3,4$ \\
\hline & Croton sp. & A & $6,7,8$ \\
\hline & Euphorbia cf. laurifolia Juss. ex Lam. & A & 5 \\
\hline \multirow[t]{4}{*}{ Fabaceae } & Crotalaria pumila Ortega & $\mathrm{H}$ & 3,4 \\
\hline & Dalea carthagenensis (Jacq.) J.F. Macbr. & A & $1,2,3,4$ \\
\hline & Fabacea-1 & A & 2 \\
\hline & Fabacea-2 & $\mathrm{H}$ & 8 \\
\hline Geraniaceae & Erodium cicutarium (L.) L'Hér. ex Aiton & $\mathrm{H}$ & 6,7 \\
\hline Lamiaceae & Salvia sp.1 & $\mathrm{H}$ & 7 \\
\hline \multirow[t]{2}{*}{ Malvaceae } & Bastardia bivalvis (Cav.) Kunth ex Griseb. & A & 4,5 \\
\hline & Malva parviflora $\mathrm{L}$. & A & 5 \\
\hline \multirow[t]{3}{*}{ Poaceae } & Aristida adscensionis L. & $\mathrm{H}$ & 6 \\
\hline & Chloris virgata Sw. & $\mathrm{H}$ & $1,2,3,5$ \\
\hline & Jarava annua (Mez) Peñail. & $\mathrm{H}$ & 8 \\
\hline Verbenaceae & Lantana sp. & A & 2 \\
\hline Zygophyllaceae & Tribulus terrestris L. & $\mathrm{H}$ & 2 \\
\hline \multirow[t]{5}{*}{ No determinada } & Especie-1 & A & 7 \\
\hline & Especie-2 & A & 5 \\
\hline & Especie-3 & A & 4 \\
\hline & Especie-4 & $\mathrm{H}$ & 7 \\
\hline & Especie-5 & $\mathrm{H}$ & 5 \\
\hline
\end{tabular}

segundo grupo, mostrándose solitaria debido a que no presentó ejemplar alguno durante la evaluación.

Las parcelas de Corralillo (2015 msnm) y de Vizcachera (2295 msnm), las cuales se encontraban en la parte media de la gradiente, conformaron el tercer grupo debido a la presencia en común de Bastardia bivalvis. Sin embargo, la parcela de Vizcachera presentó especies diferentes a la parcela de Corralillo, tales como Euphorbia cf. laurifolia y Perymenium jelskii. El cuarto grupo lo conformaron las parcelas ubicadas a mayor altitud, siendo éstas las de Mirador (2609 msnm), de Cucche (2765 msnm) y de Malca
(2900 msnm). Estas tres parcelas compartieron la presencia de Proustia cuneifolia, en tanto Verbesina saubinetioides, Croton sp. y Armatocereus matucanensis, estuvieron presentes en dos de las parcelas. Cabe notar que dentro de este grupo, las parcelas de Mirador y de Malca mostraron mayor asociación respecto a la de Cucche.

Así mismo, usando el análisis cluster según la abundancia de especies del estrato arbustivo (criterio de Morisita), se pudo observar los cuatro grupos de parcelas descritos anteriormente, aunque con un nivel de similaridad mucho menor para las parcelas 
Tabla 2. Índices de Valor de Importancia (IVI's) de las especies dentro de las parcelas del estrato arbustivo durante dos fechas de evaluación. PTb, Pampa Triste baja (1744 msnm); PTm, Pampa Triste media (1868 msnm); PTa, Pampa Triste alta (1933 msnm); Cor, Corralillo (2015 msnm); Viz, Vizcachera (2295 msnm); Mir, Mirador (2609 msnm); Cuc, Cucche (1765 msnm); Mal, Malca (2900 msnm). O-09, octubre-2009; A-10, abril-2010.

\begin{tabular}{|c|c|c|c|c|c|c|c|c|c|c|c|c|c|c|c|c|}
\hline \multirow[b]{2}{*}{ Especies } & \multicolumn{2}{|c|}{ PTb } & \multicolumn{2}{|c|}{ PTm } & \multicolumn{2}{|c|}{ PTa } & \multicolumn{2}{|c|}{ Cor } & \multicolumn{2}{|c|}{ Viz } & \multicolumn{2}{|c|}{ Mir } & \multicolumn{2}{|c|}{ Cuc } & \multicolumn{2}{|c|}{ Mal } \\
\hline & $\begin{array}{l}\text { O- } \\
09\end{array}$ & $\begin{array}{l}\text { A- } \\
10\end{array}$ & $\begin{array}{l}\text { O- } \\
09\end{array}$ & $\begin{array}{l}\text { A- } \\
10\end{array}$ & $\begin{array}{l}\text { O- } \\
09\end{array}$ & $\begin{array}{l}\text { A- } \\
10\end{array}$ & $\begin{array}{l}\text { O- } \\
09\end{array}$ & $\begin{array}{l}\text { A- } \\
10\end{array}$ & $\begin{array}{l}\text { O- } \\
09\end{array}$ & $\begin{array}{l}\text { A- } \\
10\end{array}$ & $\begin{array}{l}\text { O- } \\
09\end{array}$ & $\begin{array}{l}\text { A- } \\
10\end{array}$ & $\begin{array}{l}\text { O- } \\
09\end{array}$ & $\begin{array}{l}\text { A- } \\
10\end{array}$ & $\begin{array}{l}\text { O- } \\
09\end{array}$ & $\begin{array}{l}\text { A- } \\
10\end{array}$ \\
\hline Dicliptera sp. & & & & & & & & & & & & & & 24 & & \\
\hline Encelia canescens & & & 99 & 80 & & & & & & & & & & & & \\
\hline Helogyne sp. & & & 7 & 5 & & & & & & & & & & & & \\
\hline Ophryosporus galioides & & & 24 & 9 & & & & & & & & & & & & \\
\hline Perymenium jelskii & & & & & & & & & 77 & 84 & & & & & & \\
\hline Proustia cuneifolia & & & & & & & & & & & 51 & 25 & 55 & 61 & 90 & 78 \\
\hline Verbesina saubinetioides & & & & & & & & & & & 81 & 114 & 145 & 115 & & \\
\hline Boraginacea-1 & & & & 55 & & & & & & & & & & & & \\
\hline Armatocereus matucanensis & & & & & & & & & & & 55 & 55 & & & 44 & 39 \\
\hline Austrocylindropuntia subulata & & & & & & & & & & & & & & & 20 & 29 \\
\hline Haageocereus acranthus & 200 & 200 & 43 & 34 & & & & & & & & & & & & \\
\hline Cnidoscolus cf. basiacanthus & & & & & & & & 43 & & & & & & & & \\
\hline Croton sp. & & & & & & & & & & & 12 & 5 & & & 46 & 54 \\
\hline Euphorbia cf. laurifolia & & & & & & & & & 75 & 69 & & & & & & \\
\hline Dalea carthagenensis & & & 12 & 14 & & & & & & & & & & & & \\
\hline Fabacea-1 & & & 8 & & & & & & & & & & & & & \\
\hline Bastardia bivalvis & & & & & & & 200 & 116 & 48 & 47 & & & & & & \\
\hline Lantana sp. & & & 7 & 3 & & & & & & & & & & & & \\
\hline Especie-3 & & & & & & & & 41 & & & & & & & & \\
\hline
\end{tabular}

asociadas, entre el 30 y 50\% (Figura 2B). Para el grupo de las parcelas establecidas a mayor altitud, las de Mirador (2609 msnm) y de Cucche (2765 msnm) presentaron mayor similitud respecto a la de Malca (2900 msnm).

\section{Análisis de cobertura.}

En base a los niveles de cobertura total registrados para cada parcela del estrato arbustivo, se pudo diferenciar tres grupos, los cuales congregaron parcelas contiguas conforme la gradiente altitudinal (Figura 3). El primer grupo lo conformaron las parcelas ubicadas a menor altitud, siendo las de Pampa Triste baja (1744 msnm), de Pampa Triste media (1868 msnm), de Pampa Triste alta (1933 msnm) y de Corralillo (2015 msnm), las que mostraron coberturas menores a $3.2 \mathrm{~m}^{2}$. En contraste, la parcela de Vizcachera (2295 msnm) mostró el valor más alto de cobertura, alrededor de $23 \mathrm{~m}^{2}$, y fue la que conformó el segundo grupo. Este alto nivel de cobertura fue sostenido por los arbustos Euphorbia cf. laurifolia y Perymenium jelskii. Un tercer grupo lo constituyeron las parcelas de Mirador (2609 msnm), de Cucche (2765 msnm) y de Malca (2900 msnm), las cuales fueron establecidas a mayor altitud y presentaron valores cercanos de cobertura, alrededor de $10 \mathrm{~m}^{2}$. Sin embargo, el nivel de cobertura para este grupo fue mantenido por diferentes especies, siendo Verbesina saubinetioides más representativa en las parcelas de Mirador y de Cucche, mientras que Proustia cuneifolia en la parcela de Malca.

\section{Discusión. \\ Composición de especies.}

La Familia Asteraceae fue la que presentó mayor número de especies, seguida por las familias Fabaceae, Cactaceae, Euphorbiaceae y Poaceae (Tabla 1). Estas familias tuvieron representantes a lo largo de la gradiente altitudinal, llegando algunas de ellas a presentar especies dominantes en determinadas unidades de vegetación, tales como Haageocereus acranthus (Cactaceae), Perymenium jelskii, Verbesina saubinetioides y Proustia cuneifolia (Asteraceae), y Euphorbia cf. lauriflora (Euphorbiaceae). Estas dos últimas especies, a pesar de sus abundancias en la ladera, no fueron citadas por Brako \& Zarucchi (1993) para el departamento de Lima. Esto podría considerarse como reflejo del limitado grado de conocimiento que se tiene sobre la vegetación en la cuenca media del río Lurín. Así mismo, Ophryosporus galioides, Haageocereus acranthus y Dalea carthagenensis (de tratarse de la variedad thichocalyx), fueron señaladas como endémicas a nivel nacional, según León et al. (2006).

Los arbustos fueron la forma de vida más abundante en especies, llegando a ser dominantes en la mayoría de las unidades de vegetación. Por otro lado, se registró una baja representatividad de herbáceas en el área de estudio, siendo solo observadas durante julio-2009 y abril-2010. Esto probablemente se debería a que los niveles hídricos durante el periodo de evaluación no fueron suficientes para acarrear la masiva germinación y desarrollo de hierbas (Ramos, 
2013), considerando que estas son de carácter estacional (Braun-Blanquet, 1979; Grime, 1989). En base a la información publicada por el ANA (2015) de las tres estaciones pluviométricas ubicadas en la cuenca del río Lurín y dentro del rango altitudinal evaluado, los niveles de precipitación totales mensuales durante diciembre-2009 hasta marzo-2010 (considerados como meses de la época lluviosa 2010) estuvieron por debajo de sus correspondientes niveles históricos. De manera referencial, las estaciones pluviométricas de Antioquia (1839 msnm, 45 años de datos), de Langa (2860 msnm, 30 años de datos) y de Santiago de Tuna (2921 msnm, 45 años de datos), señalan niveles de precipitación acumulados entre diciembre-2009 y marzo-2010 de 27.7, de 165.4 y de $84.3 \mathrm{~mm}$ respectivamente, los que fueron menores a los correspondientes registros históricos de 72.6, de 244.5 y de $292.5 \mathrm{~mm}$ respectivamente (ANA, 2015). Así mismo, Ramos (2013) basado en datos de cobertura y de fenología de plantas del estrato arbustivo, así como en información sobre las actividades ganaderas y la presencia de herbáceas, argumenta que para el área de estudio posiblemente se habrían presentado condiciones de menor humedad durante el 2010, consideradas como propias de un año seco. Por otro lado, esta sequedad habría condicionado la menor producción de estructuras reproductivas de las plantas, dificultando de esta manera la determinación taxonómica de varias especies.

Agrupación de las parcelas.

Teniendo en cuenta lo registrado mediante los análisis cluster, se diferenciaron cuatro grupos, los que asociaron parcelas contiguas según la gradiente altitudinal. Sin embargo, el nivel de similaridad al considerar la abundancia de las especies (Figura 2B) fue menor al observado según la presencia-ausencia de especies (Figura 2A). Esto indicaría que, si bien las parcelas dentro de cada grupo presentaron especies comunes, la abundancia de éstas varió entre las parcelas. Por otro lado, mediante el análisis de coberturas se diferenció a tres grupos, los que también reunieron parcelas adyacentes en la gradiente (Figura 3). Teniendo en cuenta estas características, además de lo observado en los paisajes circundantes a las parcelas, se agruparon las parcelas según unidades de vegetación.

Aunque las parcelas de Pampa Triste baja (1744 msnm) y Pampa Triste media (1868 msnm) solo compartieron la presencia del cacto Haageocereus acranthus, en el paisaje circundante a la parcela de Pampa Triste baja también fue posible observar a aquellas especies registradas en la parcela de Pampa Triste media, tales como Encelia canescens y Dalea carthagenensis. Así mismo, estas especies también fueron observadas en los alrededores de la parcela de Pampa Triste alta (1933 msnm). Esto señalaría una aparente relación entre las tres parcelas, la que parece ser mayor si se tiene en cuenta los niveles de cobertura total observados, que fueron menores a $2.3 \mathrm{~m}^{2}$. Entonces, se podría considerar a estas tres parcelas ubicadas a menor altitud como perteneciente a una misma unidad de vegetación. Cabe señalar que la mayor abundancia de plantas y de especies registradas en la parcela de Pampa Triste media, posiblemente se deba a que dicha parcela se haya ubicado cerca al lecho de una quebrada seca. Si bien las quebradas son comunes en las pampas y laderas del área de estudio, se puede considerar que sus cauces presentan características algo diferentes, debido principalmente a su menor exposición del viento. Entornos con una menor exposición al viento tendrían una mayor acumulación de suelo y de semillas (Braun-Blanquet, 1979).

Por otro lado, la parcela de Corralillo (2015 msnm) también presentó características similares a estas parcelas ubicadas a menor altitud, tanto en la presencia de especies en el paisaje circundante como en el nivel de cobertura total. Sin embargo, la parcela de Corralillo se diferenció del resto de parcelas por la presencia y dominancia del arbusto Bastardia bibalvis. Si bien hubo asociación entre las parcelas de Corralillo (2015 msnm) y de Vizcachera (2295 msnm) debido a la presencia de Bastardia bivalvis, estas parcelas mostraron diferencias en las especies dominantes y en los niveles de coberturas. Mientras que Bastardia bivalvis fue dominante en la parcela de Corralillo, este arbusto no alcanzó mayor representatividad en la parcela de Vizcachera. Para esta última parcela, Euphorbia cf. laurifolia y Perymenium jelskii fueron las especies dominantes y a su vez, fueron las responsables del alto nivel de cobertura registrada. Según estas consideraciones, ambas parcelas corresponderían a unidades de vegetación diferentes.

Las parcelas establecidas a mayor altitud, de Mirador (2609 msnm), de Cucche (2765 msnm) y de Malca (2900 msnm), presentaron características comunes, tanto en la composición como en la abundancia de las especies. Sin embargo, la asociación según la composición de especies fue mayor entre las parcelas de Mirador y de Malca respecto a la de Cucche, mientras que según la abundancia, las parcelas de Mirador y de Cucche presentaron mayor similitud. Tal diferenciación en la asociación de las parcelas dentro de este grupo se debería a la presencia del arbusto Verbesina saubinetioides. Esta especie fue dominante en las parcelas de Mirador y de Cucche, mientras que no fue encontrada en la parcela de Malca, donde dominó el arbusto espinoso Proustia cuneifolia. Así mismo, éstas diferencias también fueron observadas a nivel de los respectivos paisajes circundantes, donde Verbesina saubinetioides fue registrada en menor medida en los alrededores de la parcela de Malca. En adición, ejemplares de Proustia cuneifolia, Armatocereus matucanensis y Croton sp. fueron comunes en las inmediaciones de las tres 
parcelas. Por otro lado, las tres parcelas mostraron niveles similares de cobertura total, estando alrededor de $10 \mathrm{~m}^{2}$; sin embargo, la cobertura total en las parcelas de Mirador y de Cucche fue mantenida en mayor medida por Verbesina saubinetioides, mientras que en la parcela de Malca por Proustia cuneifolia. Ante las diferencias descritas entre las parcelas de Mirador (2609 msnm) y de Cucche (2765 msnm) frente a la parcela de Malca (2900 msnm), es que sus paisajes correspondientes no fueron considerados dentro de una misma unidad de vegetación.

Unidades de vegetación.

Los paisajes que comprendieron las parcelas de Pampa Triste baja (1744 msnm), de Pampa Triste media (1868 msnm) y de Pampa Triste alta (1933 msnm), mostraron características similares, extendiéndose desde los 1720 hasta los 2000 msnm aproximadamente. Esta unidad se caracterizó por la dominancia de cactáceas, principalmente de Haageocereus acranthus y Espostoa melanostele, y por la presencia de escasos arbustos. Estos arbustos se encontraron dispersos, aumentando en número en las cercanías a las quebradas. Otras especies frecuentes fueron los arbustos Dalea carthagenensis y Encelia canescens, además del cacto Melocactus peruvianus. Así mismo, esta unidad mostró bajos niveles de cobertura y la vegetación alcanzó una altura alrededor de 30 a $50 \mathrm{~cm}$. Según estas características, esta unidad de vegetación fue reconocida como "Zona de Cactáceas”.

La segunda unidad de vegetación lo comprendería el paisaje en el que se encontró la parcela de Corralillo (2015 msnm) que, aunque compartió especies con la unidad anterior, se diferenció de ella por la presencia y dominancia del arbusto Bastardia bivalvis. Así mismo, este arbusto fue encontrado en el paisaje de Vizcachera (2295 msnm), alcanzando una mayor abundancia pero lejos de ser dominante. Por lo tanto, el paisaje de Corralillo se estaría presentando como una transición entre la Zona de Cactáceas y la unidad que correspondería al paisaje de Vizcachera, debido a la presencia de especies de ambos sectores. Sin embargo, para el presente trabajo, el paisaje de Corralillo fue considerado como una unidad de vegetación debido a su gran extensión espacial (tanto en territorio como en rango altitudinal), y fue reconocida como "Zona de Bastardia". Entonces, esta unidad de vegetación se extendería entre los 2000 y 2230 msnm aproximadamente, caracterizándose por la dominancia del arbusto Bastardia bivalvis y por la presencia de cactos y arbustos en común con la Zona de Cactáceas. Además, esta unidad presentó bajos niveles de cobertura y una altura alrededor de 30 y 50 $\mathrm{cm}$.

El bajo nivel de cobertura que caracteriza a ambas unidades de vegetación podría ser el resultado de la mayor aridez característica de estas elevaciones. Según la ONERN (1975), estos sectores estarían comprendidos en la zona de vida de Matorral desértico subtropical, el cual presenta un clima árido y semicálido, y cuyo límite altitudinal superior estaría alrededor de los 2100 msnm. Según Rivas-Martinez et al. (1988), este sector correspondería al piso bioclimático Termoandino. Así mismo, se podría considerar que ambas unidades de vegetación son equivalentes a la Zona de cactáceas mencionada por Valencia \& Franke (1980), cuyo límite superior se encuentra cercano a los $1950 \mathrm{msnm}$. Este límite altitudinal, al igual que el señalado por la ONERN (1975), se encuentra a menor elevación que el señalado en la presente área de estudio (2230 msnm). Esta diferencia en los niveles altitudinales podría deberse a que el área de estudio podría estar presentando condiciones de mayor aridez, causado principalmente por su orientación (entre $20^{\circ}$ y $65^{\circ}$ $\mathrm{NE}$ ).

Con el nivel más alto de cobertura por la presencia y abundancia de arbustos de mayor porte, así como la presencia de especies dominantes diferentes respecto a las demás parcelas, el paisaje en el que se encuentra la parcela de Vizcachera (2295 msnm) correspondería a un tipo de vegetación muy diferenciado del resto. Por tales motivos, esta unidad de vegetación fue determinada como "Zona de Arbustos Altos". La dominancia de Euphorbia cf. laurifolia y de Perymenium jelskii en esta unidad fue notoria, acompañada de la especie Bastardia bivalvis, extendiéndose desde los 2230 hasta los 2500 msnm aproximadamente. La vegetación alcanzó una altura por encima de los $180 \mathrm{~cm}$. Esta unidad de vegetación podría ser considerada como equivalente a la reconocida por Valencia \& Franke (1980) con el nombre de Zona de Carica y Jatropha, debido a lo parecido de su disposición conforme el rango altitudinal (entre 1950 y $2350 \mathrm{msnm}$ ) y a la presencia de plantas de Vasconcellea candicans (antes Carica candicans) y Jatropha macrantha en este sector del área de estudio. Aunque estas especies no fueron dominantes en los alrededores de la parcela de Vizcachera (2295 msnm), fue posible encontrar ejemplares de ellas formando agrupaciones. Así mismo, estas especies junto a Schinus molle y Baccharis gnidiifolia, fueron encontradas a partir de esta unidad de vegetación hasta la cumbre de la montaña (2957 msnm), marcando ciertas características diferentes respecto a las unidades descritas ubicadas a menor altitud. Además, la presencia de Armatocereus matucanensis fue más notoria a partir de esta unidad, encontrándose también algunos ejemplares en el paisaje de la parcela de Pampa Triste alta (1933 msnm).

En general, a partir de la Zona de Arbustos Altos hasta la cumbre de la montaña (2957 msnm), la vegetación fue más abundante en individuos y en especies, presentando además mayores niveles de coberturas, debido posiblemente a condiciones 
ambientales más favorables. Según la ONERN (1975), todo este sector (por encima de los $2100 \mathrm{msnm}$ ) estaría comprendido en la zona de vida de Estepa espinosa montano bajo, la cual presenta mayores niveles de precipitación y temperaturas más templadas en relación a la zona de vida de Matorral desértico subtropical. Teniendo en cuenta lo mencionado por Rivas-Martínez et al. (1988), todo este sector estaría comprendido dentro del piso bioclimático Mesoandino. Así mismo, Galán de Mera et al. (2004) también señalan una variación importante en la vegetación a partir de este nivel altitudinal. Estos autores, basados en las características fitosociológicas de la comunidad de plantas en la sierra central del Perú, mencionan a los 2200 msnm como límite entre sus denominadas Provincia Coquimbo-Truxillense (la que se extiende por debajo de esta altitud) y Provincia Ancashino-Paceña (a partir de esta altitud), cada una con diferentes especies y asociaciones.

Por otro lado, Weberbauer (1945) señala que alrededor de los 2400 msnm ocurre una diferenciación respecto a la distribución florística en el Piso de cactáceas columnares y de reducida vegetación herbácea. Según Weberbauer (1945), en el nivel inferior de este piso se pueden encontrar numerosas especies de cactos, mientras que en el nivel superior se nota una marcada diferencia en la presencia de plantas de mayor porte y asociaciones de bromelias (Tillandsia spp. y Puya spp.). Agrupaciones de Tillandsia sp. fueron observadas a partir del límite superior de la Zona de Arbustos Altos. Así mismo, según el mapa de cobertura vegetal del Perú generado por el MINAM (2012), alrededor de los 2500 msnm en la zona central occidental de los Andes es posible distinguir una variación en las comunidades de especies arbustivas dentro del tipo de cobertura natural de Matorral Arbustivo. Según esta fuente, en el nivel altitudinal inferior se desarrollan asociaciones arbustivas caducifolias, en tanto que en el nivel medio, que comprende hasta los 3500 msnm, se desarrollan tanto especies caducifolias como perennifolias, y se alcanza una mayor riqueza de especies. Durante el periodo de evaluación, muchas de las especies registradas en la Zona de Arbustos Altos y en las unidades a menor altitud, fueron de carácter caducifolio, mientras que por arriba de esta unidad de vegetación, se observaron varias especies de ambos hábitos foliares.

Entonces, según las consideraciones de los trabajos mencionados anteriormente, el límite altitudinal inferior de la Zona de Arbustos Altos (alrededor de los $2230 \mathrm{msnm}$ ) aparentemente sería coherente con las variaciones en la vegetación señaladas por la ONERN (1975) y por Galán de Mera et al. (2004), en tanto que el límite superior de esta unidad (alrededor de los $2500 \mathrm{msnm}$ ) estaría concordando con lo reportado por Weberbauer (1945) y por el MINAM (2012). La relación de los límites altitudinales de la Zona de
Arbustos Altos con los límites mencionados por estas fuentes, así como la diferencia en los niveles de cobertura y en la presencia y dominancia de especies respecto a las demás zonas, reflejarían lo particular que resulta esta unidad de vegetación en el área de estudio.

Los paisajes correspondientes a las parcelas de Mirador (2609 msnm) y de Cucche (2765 msnm) conformaron una misma unidad de vegetación, la cual abarcó una elevación entre 2500 y 2850 msnm aproximadamente. La especie dominante fue el arbusto Verbesina saubinetioides, acompañada de los arbustos Baccharis gnidiifolia, Proustia cuneifolia, Croton sp. y Senna birostris, del árbol Schinus molle y del cacto Armatocereus matucanensis. Además, esta unidad se caracterizó por mostrar niveles intermedios de cobertura y una altura de la vegetación entre 100 y $120 \mathrm{~cm}$. Según estas características y considerando la abundancia de arbustos espinosos, esta unidad de vegetación fue determinada como "Zona de Arbustos Subespinosos”.

La última unidad de vegetación correspondió al paisaje alrededor de la parcela de Malca (2900 msnm), la que se extendió desde los $2850 \mathrm{msnm}$ hasta la cumbre de la montaña (2957 msnm). En este sector se observaron a las mismas especies mencionadas para la Zona de Arbustos Subespinosos, con la diferencia en la dominancia del arbusto espinoso Proustia cuneifolia y la presencia del cacto Austrocylindropuntia subulata. Así mismo, en esta unidad se apreciaron niveles intermedios de cobertura y la vegetación alcanzó un porte entre 120 y $150 \mathrm{~cm}$ de alto. Debido a la dominancia de este arbusto espinoso, es que esta unidad de vegetación fue considerada como "Zona de Arbustos Espinosos”.

Debido al cierto grado de desarrollo de estructuras de defensa física contra la herbivoría y a la disposición en la gradiente altitudinal, se podría considerar a estas dos últimas unidades de vegetación como equivalentes a la Zona baja y alta de arbustos espinosos mencionados por Valencia \& Franke (1980). Estas zonas descritas por estos autores presentan características semejantes, que ante la ausencia de una Zona de bosque ralo perennifolio, muy probablemente se encontrarían unidas y serían parte de la misma formación vegetal.

Por otro lado, la variación en la dominancia de las especies en el sector alto de la montaña podría deberse al efecto de ciertas condiciones ambientales, las que estarían restringiendo la distribución más elevada de Verbesina saubinetioides, por encima de los 2850 msnm, y favoreciendo la de Proustia cuneifolia. Sin embargo, parecería más probable el que ambas especies estén relacionadas al efecto del pastoreo debido a sus características de palatabilidad. Varias especies del género Verbesina son consideradas como plantas de alta calidad forrajera, por lo que suelen ser preferidas por el ganado (Benavides, 1998; Carranza 
et al., 2003; Olivera et al., 2011). Esta preferencia podría estar ocurriendo sobre Verbesina saubinetioides en el área de estudio, ya que durante la evaluación (julio-2009 y enero-2010) se observaron tallos y hojas de varios individuos con signos de depredación, principalmente en las partes altas de su distribución (a partir del paisaje de Cucche). En contraste, Proustia cuneifolia presenta estructuras de defensa física frente a la depredación de sus partes aéreas, tales como numerosas espinas y hojas dentadas y medianamente coriáceas (Ceroni, 2003).

Considerando que en estas zonas altas es donde muchos ganaderos tienden a asentarse durante la época lluviosa, es de esperar un mayor efecto de la herbivoría. Ante estas condiciones, se estaría favoreciendo el desarrollo de arbustos espinosos frente a otros arbustos palatables, debido en gran medida a la selección de estas últimas plantas por parte del ganado (Braun-Blanquet, 1979; Terradas, 2001; Parra \& Torres, 2004). Entonces, podría estar ocurriendo que la mayor presión ganadera realizada en el sector alto del área de estudio estaría provocando la progresiva disminución de Verbesina saubinetioides, y por tanto la consecuente reducción de la competencia por espacio y recursos, favoreciendo la proliferación y un mayor desarrollo de Proustia cuneifolia conforme la altitud.

En general, las cinco unidades de vegetación y sus rangos aquí propuestos, para una ladera de orientación Norte-Este de la cuenca media del río Lurín (Figuras 4 y 5), parecen coincidir con lo reportado por otros estudios realizados en los Andes Occidentales del centro del Perú (Tabla 3). Las altitudes señaladas para cada unidad de vegetación en el área de estudio varían en función de la pendiente de la ladera y de su orientación, por lo que los límites altitudinales mencionados serían referenciales. Así mismo, estos límites no son claros debido a que están caracterizados por el desarrollo de formaciones transicionales.

Además de la Zona de Bastardia, se pudo observar otras dos zonas transicionales pero de menor extensión espacial, las que presentaron especies características o dominantes de ambas unidades de vegetación en vecindad. Además, se apreció que en estas zonas transicionales ciertas plantas presentaron sus límites de distribución altitudinal o una reducción

Tabla 3. Formaciones vegetales mencionadas por otros autores para la vertiente occidental de los Andes del centro del Perú (rango altitudinal en msnm entre paréntesis).

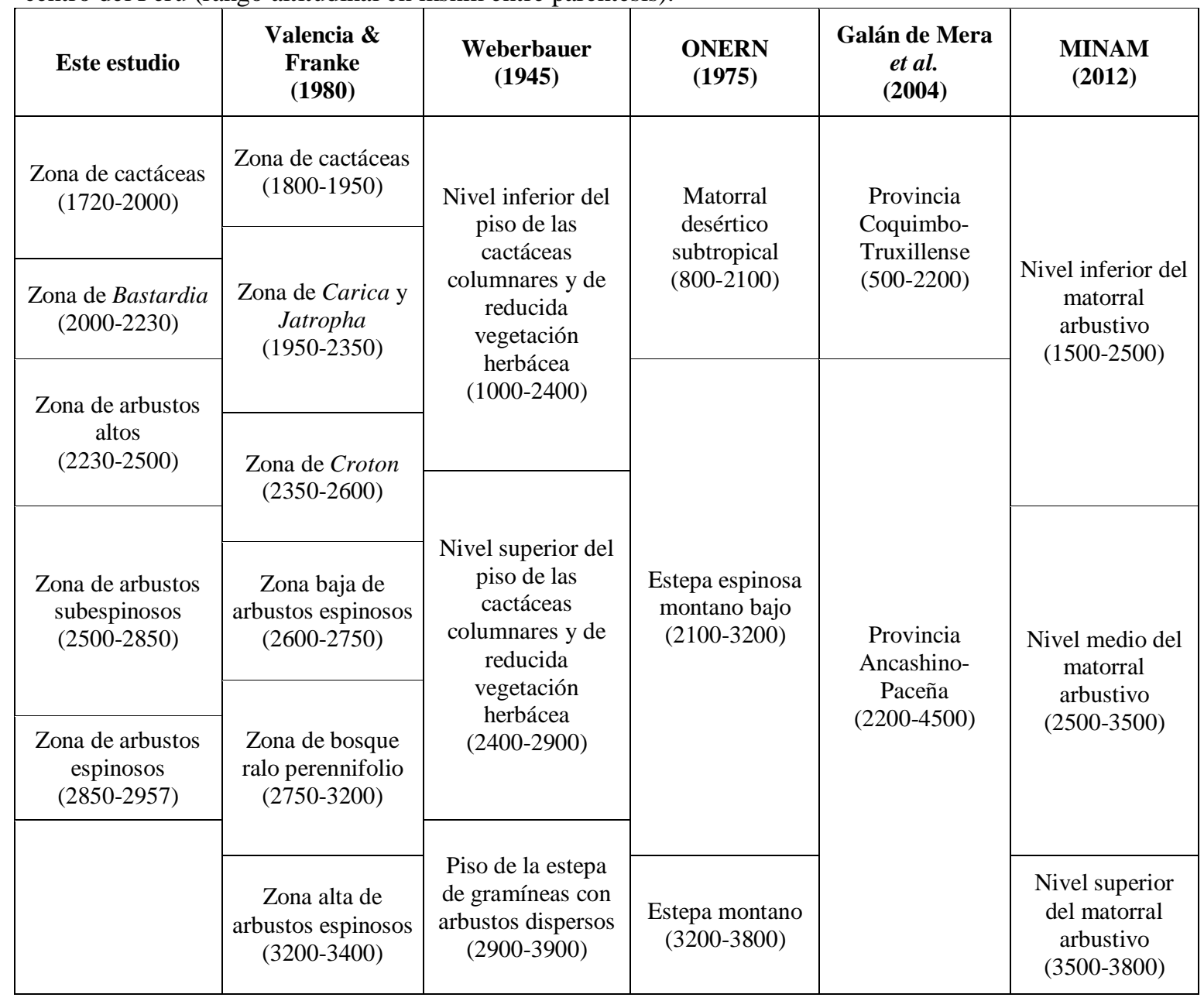


notoria en sus abundancias. En la transición entre la Zona de Arbustos Altos y la Zona de Arbustos Subespinosos (alrededor de $2500 \mathrm{msnm}$ ) fue posible observar una disminución de plantas y posterior ausencia de Euphorbia cf. laurifolia y Bastardia bivalvis, acompañado de un progresivo aumento de Verbesina saubinetioides y la aparición y proliferación de Proustia cuneifolia conforme la altitud. Así mismo, en el sector transicional entre la Zona de Arbustos Subespinosos y la Zona de Arbustos Espinosos (alrededor de $2850 \mathrm{msnm}$ ) ocurrió una disminución de Verbesina saubinetiodes y de Perymenium jelskii conforme la altitud, llegando esta última a desaparecer, mientras que Proustia cuneifolia se fue haciendo más numerosa y dominante.

\section{Conclusiones.}

La familia con mayor riqueza de especies fue Asteraceae, seguida por Fabaceae, Cactaceae, Euphorbiaceae y Poaceae.

Los arbustos fueron la forma de vida dominante y la que contó con mayor número de especies durante el periodo de evaluación.

Las unidades de muestreo contiguas en la gradiente altitudinal presentaron ciertas similitudes según sus niveles de cobertura total, así como en la composición y abundancia/dominancia de especies del estrato arbustivo.

Se reconocieron cinco unidades de vegetación a lo largo de la gradiente: (a) Zona de Cactáceas (17202000 msnm); (b) Zona de Bastardia (2000-2230 msnm); (c) Zona de Arbustos Altos (2230-2500 msnm); (d) Zona de Arbustos Subespinosos (2500$2850 \mathrm{msnm}) ;$ y (e) Zona de Arbustos Espinosos (2850-2957 msnm).

La distribución de las unidades de vegetación fue coherente con lo que se ha reportado en la literatura para las vertientes occidentales de los Andes del centro del Perú, dentro de la gradiente altitudinal estudiada.

\section{Agradecimientos.}

Los autores agradecen al equipo de campo de la UNALM, en especial a Andrea Ramos, Sarah Landeo, José Mendoza, Jesús Muñoz, Roció Egoávil, Zara Sánchez, Cciary Alegría, Fanny García, Indira Alva, Claudia Parra, Alfredo Butrón y Jenifer Jara. A Santiago Mendoza por su esfuerzo, experiencia y compromiso durante el trabajo de campo. A los pobladores de la comunidad de Cochahuayco por su hospitalidad y por las facilidades brindadas durante las coordinaciones en campo. A Gary Falla por la diagramación del perfil altitudinal. A la profesora Mercedes Flores (UNALM), profesora Graciela Vilcapoma (UNALM), José Alegría, Arturo Granda, Sulma Faustino y Michael Vega, por la determinación taxonómica de las especies vegetales. A los profesores Juan Torres (UNALM) y Aldo Ceroni (UNALM) por sus valiosos comentarios, así como a la profesora Ana Vargas (UNALM) por el apoyo en la parte estadística.

\section{Literatura citada.}

ANA (Autoridad Nacional del Agua). 2015. Datos Pluviométricos. Perú. Consultado: 07 de abril del 2015 $<$ www.ana.gob.pe>.

Benavides J. 1998. Árboles y arbustos forrajeros: una alternativa agroforestal para la ganadería. En: Rosales M., Murgueitio E., Osorio H., Speedy A. \& Sánchez M., eds. Agroforestería para la Producción Animal en Latinoamérica. FAO. 367-394.

Braun-Blanquet J. 1979. Fitosociología: bases para el estudio de las comunidades vegetales. H. Blume Ediciones. España. 820 pp.

Brako L. \& Zarucchi J. 1993. Catalogue of the flowering plants and gymnosperms of Peru. Missouri Botanical Garden. U.S.A. 1284 pp.

Calderón N., Ceroni A. \& Ostolaza C. 2004. Distribución y estado de conservación del género Haageocereus (Familia Cactaceae) en el departamento de Lima, Perú. Revista Ecología Aplicada. 3(1,2): 17-22.

Carranza M., Sánchez L., Pineda M. \& Cuevas R. 2003. Calidad y potencial forrajero de especies del bosque tropical caducifolio de la Sierra de Manantlán, México. Revista Agrociencia. 37(2): 203-210.

Castro V. 2006. Taxonomía de la familia Cactaceae en el valle del río Chillón, Lima: cerro Umarcata y quebrada Oropel. Tesis para optar el grado de Magister Scientiae. Universidad Nacional Agraria La Molina. Lima, Perú. 96 pp.

Ceroni A. 2003. Distribución altitudinal de las especies vegetales más frecuentes de las lomas de Atiquipa del desierto sur del Perú (Arequipa). Revista Zonas Áridas. 7: 177-198.

COFOPRI (Organismo de Formalización de la Propiedad Informal). 2007. Mapa Topográfico de Antioquia (Hoja: 25J-I-NE). Escala 1:2500. Datum: SAD_56. Lima, Perú.

Daniel W. 2002. Bioestadística, base para el análisis de las ciencias de la salud. Editorial Limusa. México. 755 pp.

Galán de Mera A., Baldeón S., Beltrán H., Benavente M. \& Gómez J. 2004. Datos sobre la vegetación del centro del Perú. Acta Botanica Malacitana. 29: 89-115.

Grime P. 1989. Estrategias de adaptación de las plantas y procesos que controlan la vegetación. Editorial Limusa. México. $291 \mathrm{pp}$.

Hammer Ø. 2011. Reference manual of PAST, Paleontological Statistics, version 2.09. Natural History Museum, University of Oslo. Norwegian. 214 pp.

Krebs C. 1999. Ecological methodology. University of British Columbia. U.S.A. 620 pp.

León B., Roque J., Ulloa Ulloa C., Jørgensen P., Pitman N. \& Cano A. (Eds.). 2006. Libro rojo de las plantas endémicas del Perú. Revista Peruana de Biología. Edición especial, 13(2): 971 pp.

Matteucci S. \& Colma A. 1982. Metodología para el estudio de la vegetación. Secretaria General de la Organización de los Estados Americanos, Programa Regional de Desarrollo Científico y Tecnológico. U.S.A. 169 pp.

MINAM (Ministerio del Ambiente). 2012. Memoria descriptiva del Mapa de cobertura del Perú. Perú. 76 pp.

Mueller-Dombois D. \& Ellenberg H. 1974. Aims and methods of vegetation ecology. John Wiley \& Sons, Inc. U.S.A. 547 pp. 
Olivera P., Tamariz C., Castillo F. \& Choy M. 2011. Características de suelo y usos tradicionales de especies vegetales en la Provincia de Huaraz, Ancash, Perú. Revista ECIPerú. 8(1): 44-47.

ONERN (Oficina Nacional de Evaluación de Recursos Naturales). 1975. Inventario y evaluación de los recursos naturales de la zona del proyecto Marcapomacocha. Perú. Vol. 1. 585 pp.

Ostolaza C. 2006. El género Armatocereus Backeberg. Revista Zonas Áridas. 10: 144-154.

Parra F. \& Torres J. 2004. Procesos de desertificación en las cuencas andinas: el Pachachaca, un caso en las montañas de Huancavelica, Perú. Revista Zonas Áridas. 8: 48-56.

Prina A. \& Alfonso G. 2002. La importancia actual de las prospecciones florísticas en biología de la conservación. Una experiencia en el árido del centro-oeste de Argentina. Ecosistemas, Revista Científica y Técnica de Ecología y Medio Ambiente. 11(3). $<$ www.revistaecosistemas.net $>$.

Ramos D. 2013. Caracterización y estacionalidad de la vegetación a lo largo de una gradiente altitudinal en la cuenca media del río Lurín, comunidad de Cochahuayco, provincia de Huarochirí, Lima. Tesis para optar el título profesional de Biólogo. Universidad Nacional Agraria La Molina. Lima, Perú. 108 pp.
Rivas-Martínez S., Tovar O. \& Galán de Mera A. 1988. Pisos bioclimáticos y cultivos del Perú. Universidad Complutense de Madrid y Universidad Nacional Mayor de San Marcos. España. 70 pp.

Rodríguez L. \& Young K. 2000. Biological diversity of Peru: Determining priority areas for conservation. A Journal of the Human Environment. 29(6): 329-337.

Soriano P. \& Ruiz A. 2003. Arbustales xerófilos. En: Aguilera M., Azócar A. \& González-Giménez E., eds. Biodiversidad en Venezuela. Fundación Polar, Ministerio de Ciencia y Tecnología. Venezuela. 696715.

Terradas J. 2001. Ecología de la vegetación, de la ecofisiología de las plantas a la dinámica de comunidades y paisajes. Ediciones Omega. España. 760 pp.

Tropicos.org. 2015. Missouri Botanical Garden. U.S.A. Consultado: 07 de abril del 2015 <www.tropicos.org>.

Valencia N. \& Franke I. 1980. El bosque de Zárate y su conservación. Boletín de Lima. 7: 76-86; 8: 26-35.

Weberbauer A. 1945. El mundo vegetal de los Andes Peruanos. Estación Experimental Agrícola de La Molina, Ministerio de Agricultura. Perú. 776 pp.

\section{Figuras}
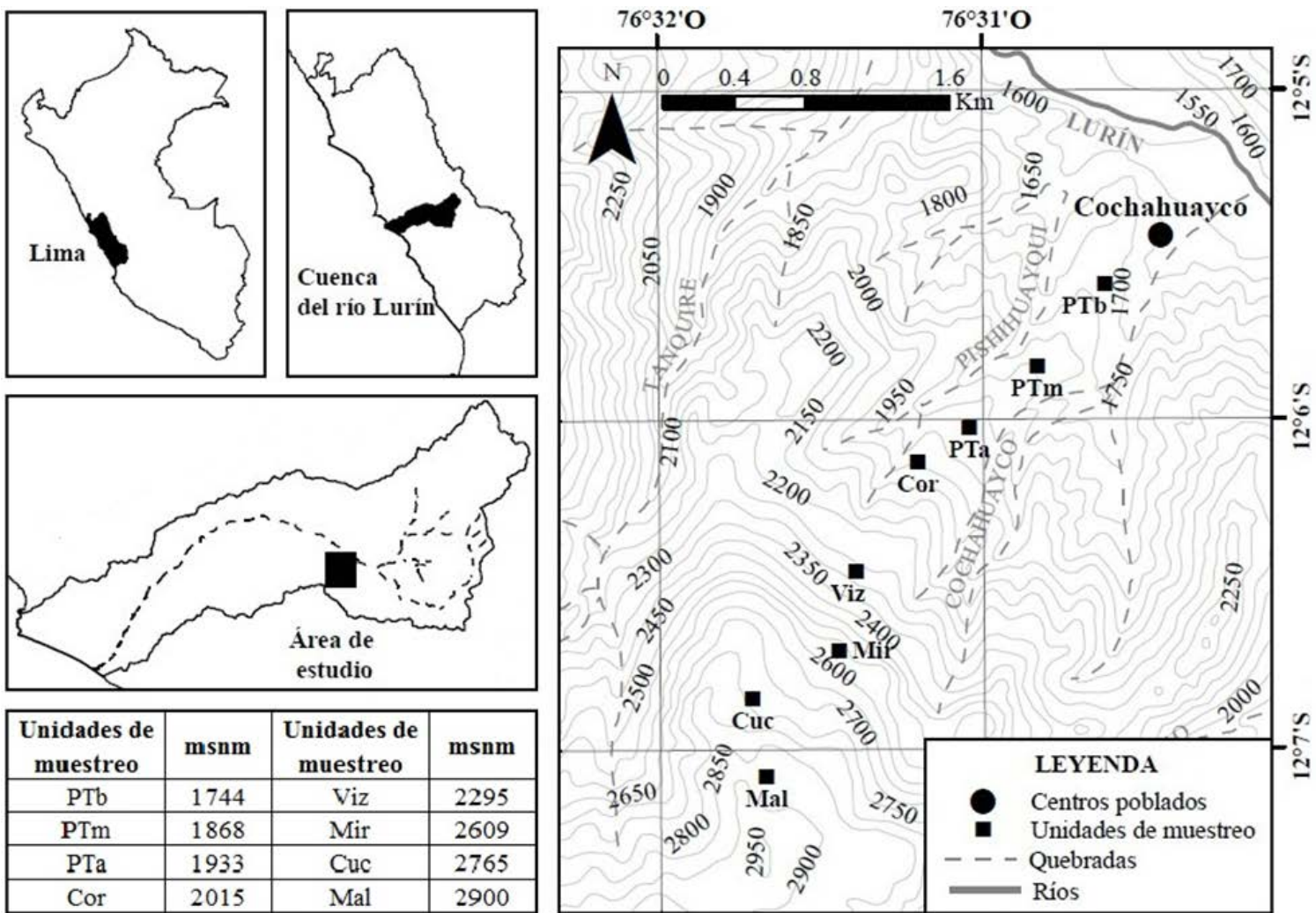

Figura 1. Área de estudio y unidades de muestreo, comunidad de Cochahuayco, cuenca media del río Lurín, Lima. PTb, Pampa Triste baja; PTm, Pampa Triste media; PTa, Pampa Triste alta; Cor, Corralillo; Viz, Vizcachera; Mir, Mirador; Cuc, Cucche; Mal, Malca. 


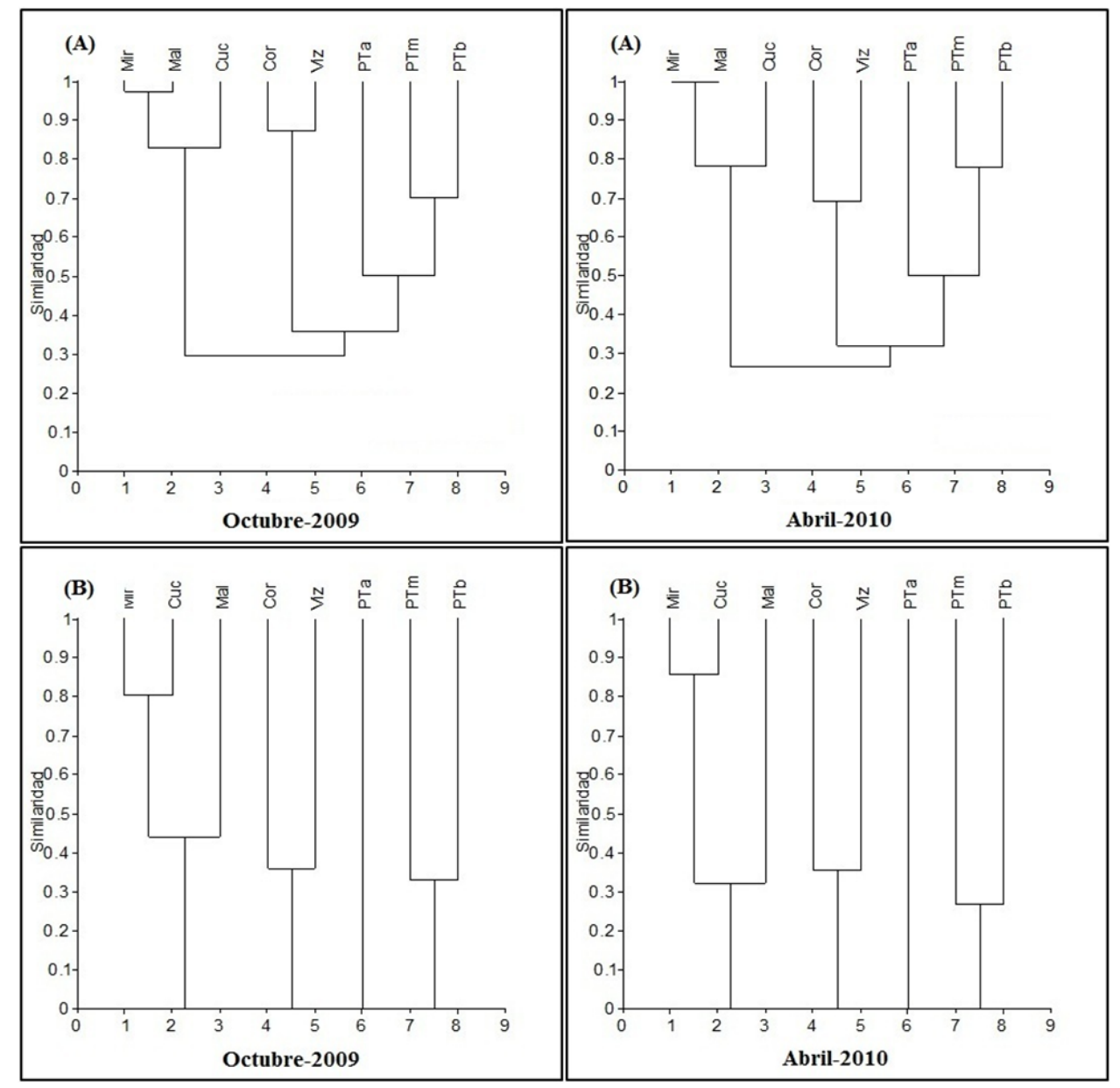

Figura 2. Dendrogramas de parcelas del estrato arbustivo según (A) el criterio de Raup-Crick y (B) el criterio de Morisita, durante dos de las fechas de evaluación. PTb, Pampa Triste baja (1744 msnm); PTm, Pampa Triste media (1868 msnm); PTa, Pampa Triste alta (1933 msnm); Cor, Corralillo (2015 msnm); Viz, Vizcachera (2295 msnm); Mir, Mirador (2609 msnm); Cuc, Cucche (1765 msnm); Mal, Malca (2900 msnm).

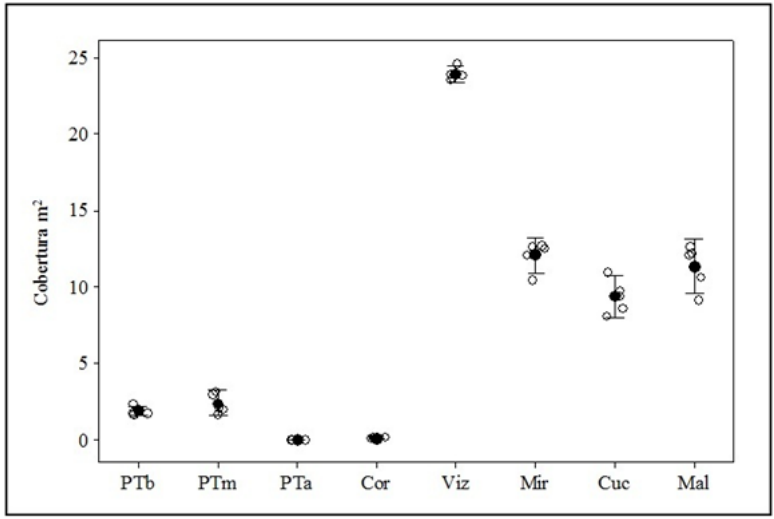

Figura 3. Niveles de Cobertura total $\left(\mathrm{m}^{2}\right)$ en las 8 parcelas del estrato arbustivo durante el periodo evaluado. PTb, Pampa Triste baja (1744 msnm); PTm, Pampa Triste media (1868 msnm); PTa, Pampa Triste alta (1933 msnm); Cor, Corralillo (2015 msnm); Viz, Vizcachera (2295 msnm); Mir, Mirador (2609 msnm); Cuc, Cucche (1765 msnm); Mal, Malca (2900 msnm). 


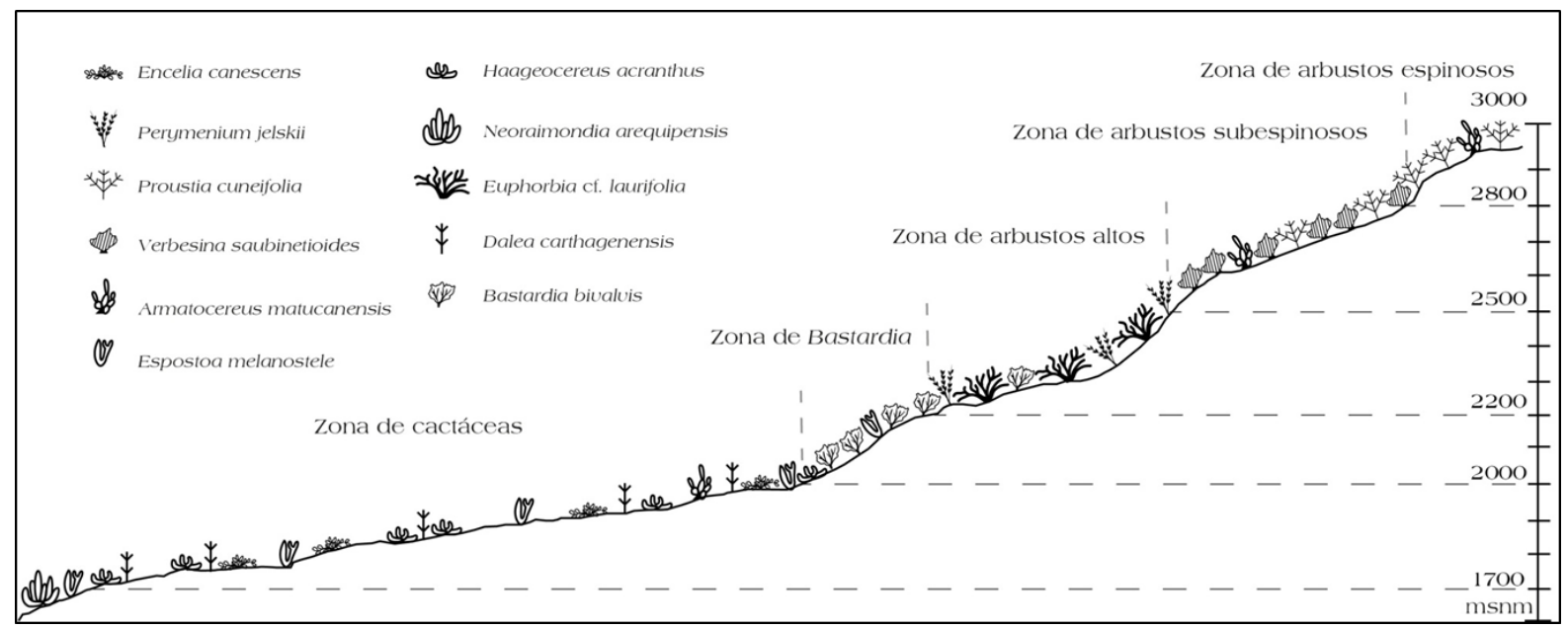

Figura 4. Perfil altitudinal de la vegetación en una gradiente altitudinal de la Comunidad de Cochahuayco, cuenca media del río Lurín, Lima.

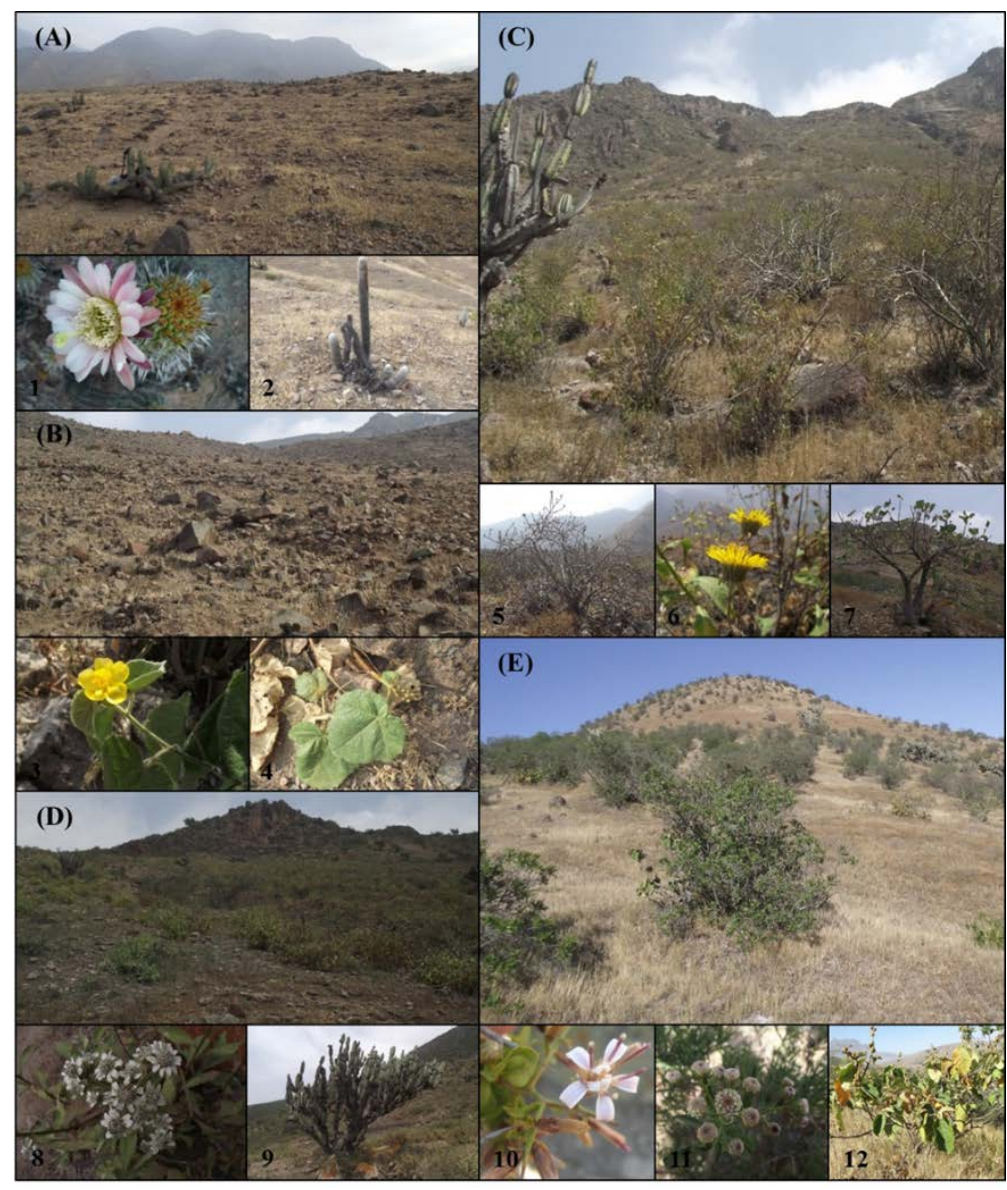

Figura 5. Unidades de vegetación y sus respectivas especies representativas (debajo de cada unidad), en una gradiente altitudinal de la comunidad de Cochahuayco, cuenca media del río Lurín, Lima. (A) Zona de Cactáceas (1720-2000 msnm); (B) Zona de Bastardia (2000-2230 msnm); (C) Zona de Arbustos Altos (2230-2500 msnm); (D) Zona de Arbustos Subespinosos (2500-2850 msnm); (E) Zona de Arbustos Espinosos (2850-2957 msnm). 1, Haageocereus acranthus; 2, Espostoa melanostele; 3, Bastardia bivalvis; 4, Cnidoscolus cf. basiacanthus; 5, Euphorbia cf. laurifolia; 6, Perymenium jelskii; 7, Vasconcellea candicans; 8, Verbesina saubinetioides; 9, Armatocereus matucanensis; 10, Proustia cuneifolia; 11, Baccharis gnidiifolia; 12, Croton sp.. 
Anexo 1. Lista de especies vegetales registradas fuera de las parcelas del estrato arbustivo y herbáceo. A, arbusto; Ar, árbol; C, cacto; H, hierba; B, bejuco; E, epífita. 1, Pampa Triste baja (1744 msnm); 2, Pampa Triste media (1868 msnm); 3, Pampa Triste alta (1933 msnm); 4, Corralillo (2015 msnm); 5, Vizcachera (2295 msnm); 6, Mirador (2609 msnm); 7, Cucche (2765 msnm); 8, Malca (2900 msnm).

\begin{tabular}{|c|c|c|c|}
\hline Familia & Especie & Habito & Paisajes \\
\hline Anacardiaceae & Schinus molle L. & $\mathrm{Ar}$ & $5,6,7,8$ \\
\hline \multirow[t]{6}{*}{ Asteraceae } & Baccharis gnidiifolia Kunth & A & $5,6,7,8$ \\
\hline & Galinsoga sp. & $\mathrm{H}$ & 8 \\
\hline & Onoseris sp. & $\mathrm{H}$ & $2,6,7$ \\
\hline & Porophyllum ruderale (Jacq.) Cass. & $\mathrm{H}$ & 1,2 \\
\hline & Senecio richii A. Gray & $\mathrm{H}$ & 7 \\
\hline & Zinnia peruviana (L.) L. & $\mathrm{H}$ & $1,2,3,4,5$ \\
\hline Boraginaceae & Heliotropium sp. & $\mathrm{H}$ & 2 \\
\hline Bromeliaceae & Tillandsia sp. & $\mathrm{He}$ & $6,7,8$ \\
\hline \multirow[t]{5}{*}{ Cactaceae } & Espostoa melanostele (Vaupel) Borg & $\mathrm{C}$ & $1,2,3,4$ \\
\hline & Haageocereus pseudomelanostele (Werderm. \& Backeb.) Backeb. & $\mathrm{C}$ & 1,2 \\
\hline & Melocactus peruvianus Vaupel & $\mathrm{C}$ & $1,2,3,4$ \\
\hline & Mila nealeana Backeb. & $\mathrm{C}$ & 1,2 \\
\hline & Neoraimondia arequipensis Backeb. & $\mathrm{C}$ & 1 \\
\hline Calceolariaceae & Calceolaria glauca Ruiz \& Pav. & $\mathrm{H}$ & 7 \\
\hline Caricaceae & Vasconcellea candicans (A. Gray) A. DC. & $\mathrm{Ar}$ & $5,6,7,8$ \\
\hline \multirow[t]{2}{*}{ Convolvulaceae } & Ipomoea nationis (Hook.) G. Nicholson & $\mathrm{B}$ & 5,6 \\
\hline & Ipomoea sp. & $\mathrm{B}$ & 7 \\
\hline Euphorbiaceae & Jatropha macrantha Müll. Arg. & A & $5,6,7,8$ \\
\hline Fabaceae & Senna birostris (Dombey ex Vogel) H.S. Irwin \& Barneby & A & $6,7,8$ \\
\hline \multirow[t]{2}{*}{ Geraniaceae } & Balbisia verticillata Cav. & A & 8 \\
\hline & Erodium moschatum (L.) L'Hér. ex Aiton & $\mathrm{H}$ & 8 \\
\hline Lamiaceae & Salvia sp.2 & A & 7,8 \\
\hline Nyctaginaceae & Boerhavia coccinea Mill. & $\mathrm{H}$ & 2 \\
\hline Plantaginaceae & Plantago limensis Pers. & $\mathrm{H}$ & 8 \\
\hline Polemoniaceae & Phlox gracilis (Douglas ex Hook.) Greene & $\mathrm{H}$ & 8 \\
\hline \multirow[t]{2}{*}{ Solanaceae } & Browallia americana $\mathrm{L}$. & $\mathrm{H}$ & 5,6 \\
\hline & Leptoglossis schwenckioides Benth. & $\mathrm{H}$ & 2 \\
\hline \multirow[t]{2}{*}{ Verbenaceae } & Aloysia scorodonioides (Kunth) Cham. & A & 5 \\
\hline & Verbena cf. pogostoma Klotzsch ex Walp. & $\mathrm{H}$ & $6,7,8$ \\
\hline
\end{tabular}

${ }^{1}$ Departamento Académico de Biología, Universidad Nacional Agraria La Molina. Av La Molina s/n, LimaPerú, danielramosh7@gmail.com.

2 Jardín Botánico “Octavio Velarde Núñez”. Departamento Académico de Biología, Facultad de Ciencias, Universidad Nacional Agraria La Molina. Av La Molina s/n, Lima-Perú, vcastro@lamolina.edu.pe.

${ }^{3}$ Laboratorio de Ecología de Procesos, Departamento Académico de Biología, Facultad de Ciencias, Universidad Nacional Agraria La Molina. Av La Molina s/n, Lima-Perú, esi7@yahoo.com. 